\section{Welcome to Infectious Disease Reports: a message from the Editor}

\section{David M. Aronoff}

Division of Infectious Diseases, Department of Internal Medicine, The University of Michigan Health System, Ann Arbor, MI, USA

Welcome to the new online-only, international, Open Access, peer-reviewed journal, Infectious Disease Reports (IDR). It is a profound honor to lead this new journal, and I would like to share with you my vision for IDR and take this opportunity to encourage you to submit your work for peer review. It is a great challenge to define the scope of a new infectious disease journal given the wide breadth of our rapidly-evolving field. Infectious diseases present both ongoing and emerging threats to human health. In addition to the "usual offenders" that reap havoc on global human populations (e.g., malaria, tuberculosis, pneumonia, HIV/AIDS), we regularly find ourselves challenged by unexpected and emerging infectious disease threats. Recent examples include epidemics/pandemics (e.g., H1N1 influenza, Ebola virus, severe acute respiratory syndrome [SARS]); large-scale outbreaks (e.g., Vibrio cholerae, Escherichia coli, Norovirus, other food-borne infections); antimicrobial and antiviral resistance (e.g., extremely drugresistant tuberculosis [XDR-TB], extendedspectrum beta lactamases, antiviral-resistant HIV); and the transcontinental migration/ importation of infectious agents (e.g., monkeypox, West Nile virus, tuberculosis). In this light, the scope of IDR must be broad, to cap- ture and address the rapidly-shifting global challenges faced by the ID community.

The editorial staff at IDR are committed to insuring that manuscripts published here are novel and meet the needs of a diverse audience. Because our field of infectious diseases includes longstanding problems and emerging threats, IDR seeks to publish manuscripts including:

- $\quad$ expert reviews (both invited and unsolicited) that identify current gaps in our knowledge

- original investigations (including basic science, translational and clinical research)

- case series and case reports, which are often the heralds of emerging ID threats.

In addition, IDR encourages the submission of manuscripts that include the use of novel research tools or address our field from a multidisciplinary perspective. Examples of innovative areas that could be targeted for reviews or original manuscripts include studies of human microbial ecology or the use of systems biology, nanotechnology, and metagenomics to address problems in infectious diseases. I envision manuscripts in $I D R$ addressing the following areas (in no particular order):

- international health/pandemics

- microbial pathogenesis and host immunology

- virology

- bacteriology

- mycology

- parasitology

- vaccinology

- epidemiology

- diagnostics (including novel, rapid, and field-based methods)

- treatment.
Correspondence: David M. Aronoff, 4618-C Med. Sci. Bldg. II, 1150 W. Medical Center Dr., Ann Arbor, MI 48109-5623, USA

E-mail: daronoff@umich.edu

Received for publication: 8 September 2009. Accepted for publication: 8 September 2009 .

This work is licensed under a Creative Commons Attribution 3.0 License (by-nc 3.0)

CC Copyright D.M. Aronoff 2009

Infectious Disease Reports 2009; 1:e1

doi:10.4081/idr.2009.e1

The Open Access, online-only era is upon us. An exciting consequence of online access is the ease with which we can reach out across geographical, cultural, and political barriers to communicate about the latest infectious disease problems and solutions. In many international regions, Open Access is seen as a natural, financially sustainable alternative to standard publishing. PAGEPress, the publisher of $I D R$, is committed to offering a publication platform to developing and developed countries alike.

We have populated the Editorial Board of $I D R$ with a balance of young (emerging) and established infectious disease experts to ensure that our manuscripts are current, of wide interest, address controversies and unanswered questions, and help stimulate further advances in the field. I strongly encourage you to submit your work to IDR. I look forward to seeing $I D R$ grow into a major infectious disease journal that makes robust contributions to controlling the global threat of human infection. 